\title{
Corrosion behaviour of Ni-Co alloy coatings at Kish Island (marine) atmosphere
}

\author{
KOUROSH SHARIFI ${ }^{\dagger} * *$ and MOHAMMAD GHORBANI ${ }^{\dagger \dagger}$ \\ ${ }^{\dagger}$ Science and Engineering Department, Sharif University of Technology, Kish Island, P.O. Box: 79417-76655, Iran \\ ${ }^{\dagger}$ Department of Material Science and Engineering, Sharif University of Technology, Azadi Ave, Tehran, \\ P.O. Box: 11155-9466, Iran
}

MS received 15 December 2012; revised 3 July 2013

\begin{abstract}
In this study, the corrosion behaviour of Ni-Co alloys with low Co content, electroplated on steel substrate in sulphate bath, was investigated. The morphology of coatings was studied by optical and SEM microscopy. The corrosion products were analyzed using EDX. The results showed that Ni-1\%Co coatings had a better corrosion resistance $0.30,0.92$ and 3.75 mpy for atmospheric, salt spray and polarization tests, respectively. These are $0.41,1.20$ and $5.40 \mathrm{mpy}$ for pure nickel coatings that indicate the least corrosion resistance. Surface analysis revealed the presence of oxides, sulphides and chlorides in corrosion products.
\end{abstract}

Keywords. Atmospheric corrosion; nickel-cobalt coating; polarization curve.

\section{Introduction}

The aim of this study is to investigate the corrosion behaviour of $\mathrm{Ni}-\mathrm{Co}$ electrodeposition in marine environment by three methods consisting of atmospheric, salt spray and polarization tests. Nickel alloy coatings are achieved by electroplating or electroless methods, either directly on the steel or over an intermediate coating of copper. In comparison with pure nickel, nickel alloy possesses good adhesion, mechanical properties, corrosion resistance, thermal stability and excellent magnetic properties. It has a wide variety of applications in the aerospace, electronic, petrochemical and medical fields. Nickel alloy shows corrosion resistance, especially in an environment where materials have to withstand high temperatures and oxidizing conditions specially in seawater. Due to their hardness combined with a high corrosion resistance, $\mathrm{Ni}-$ Co alloys are considered as a potential system to replace hard chromium coatings. Ni has the same strength as steel, while Ni coatings tarnish in corrosive environments (ASM Handbook 1993; ASM Handbook 1994; Correia and Machado 2000; Lupi and Pilone 2001; Golodnitsky et al 2002; Schweitzer 2004; Chi et al 2005; Qiao et al 2005; Wang et al 2005; Ahmad 2006; Wang et al 2006; Wolfgang et al 2006; Dolati et al 2007; Cisse et al 2010; San and Nazir 2010).

It has been shown that for a typical Watts bath, chloride and acetate electrolytes as well as sulphate and sulfamate baths, $\mathrm{Ni}-\mathrm{Co}$ alloy gets rich in $\mathrm{Co}$, thus resulting

\footnotetext{
*Author for correspondence (kourosh_sharifi@yahoo.com)
}

in an anomalous deposition. This is because the adsorption ability of $\mathrm{Co}(\mathrm{OH})^{+}$is higher than that of $\mathrm{Ni}(\mathrm{OH})^{+}$. At a low quantity of $\mathrm{Co}$, the deposition behaviour of this alloy will be under mass transfer control, and it does not show any anomalous behaviour. Hydrogen and oxygen evolution reaction (HER and OER) are two challenges for nickel plating (Correia and Machado 2000; Lupi and Pilone 2001; Golodnitsky et al 2002; Chi et al 2005; Wolfgang et al 2006; Dolati et al 2007; Orinakova et al 2008; Eliaz et al 2010; Ebadi et al 2010).

The Co content of the alloy plays the main role in physical and electrochemical properties of the coating. Co increases the resistance carburization of Ni. Generally, this coating has three different structures consisting of pure $f c c$ (which would exist for pure nickel), $f c c$ and $h c p$ phases (as Co content increases) and pure hcp (for pure cobalt). The corrosion properties of the alloy depend on phase structure and grain size, and the best corrosion resistance will be for the $f c c$ phase which has the biggest grain size. The smaller the grain size, the larger will be the total boundary surface area per unit volume which is vulnerable to corrosion (Tury et al 2006, 2007).

Atmospheric corrosion may be divided into dry, damp and wet categories and weather condition is classified into rural, urban, industrial and marine environments. Some important factors affecting on atmospheric corrosion behaviour are relative humidity, temperature, sulphur dioxide content, hydrogen sulphide content, chloride content, the amount of rainfall, dust and geographical location. Even the position of the exposed metal exhibits marked influences on the corrosion behaviour. Some 
gaseous agents that have a considerable importance in atmospheric corrosion are: $\mathrm{O}_{2}, \mathrm{H}_{2} \mathrm{O}_{2}, \mathrm{SO}_{2}, \mathrm{H}_{2} \mathrm{~S}, \mathrm{CO}_{2}, \mathrm{NO}_{2}$, $\mathrm{HNO}_{3}, \mathrm{NH}_{3}, \mathrm{HCl}, \mathrm{Cl}_{2}, \mathrm{HCHO}$ and $\mathrm{HCOOH}$. Nickel occupies an intermediate position in the electrochemical series. The possible general oxidation process for $\mathrm{Ni}$ and $\mathrm{Co}$ is:

$$
\begin{aligned}
& 2 \mathrm{H}_{2} \mathrm{O}+\mathrm{Me} \rightarrow \mathrm{Me}(\mathrm{OH})_{2} \cdot \mathrm{H}_{2} \mathrm{O}+\mathrm{H}^{+}+e^{-}, \\
& \mathrm{Me}(\mathrm{OH})_{2} \cdot \mathrm{H}_{2} \mathrm{O}+\mathrm{OH}^{-} \rightarrow \\
& \mathrm{MeOOH} \cdot \mathrm{H}_{2} \mathrm{O}_{1+x}+e^{-}+(1-x) \mathrm{H}_{2} \mathrm{O},
\end{aligned}
$$

where Me represents the Co and Ni species. Water may be absorbed on the surface in the molecular or associated form and oxygen atoms bond to the substrate so that a charge flow from the water molecule to the substrate is produced. The adsorption of water provides the electrolyte required for the formation of a corrosion cell on the metallic substrate. The water layers increase in thickness by the time and adsorb the salt from the atmosphere resulting in better conductivity of the electrolyte (ASM Handbook 1992; Schweitzer 2004, 2007; Shreir et al 2000; Tury et al 2007; San and Nazir 2010).

The salt spray (fog) test is performed according to ASTM B117 (Standard Practice for Operating Salt Spray (fog) Testing Apparatus). Constant humid surface, elevated temperature and high chloride concentration (effect on corrosion depends on the type of protection the coating offers) are some of the problems associated with this test (Schweitzer 2006).

Meena Srivastava et al (2006) investigated the corrosion resistance of $\mathrm{Ni}-\mathrm{Co}$ alloys electrodeposited on brass and mild steel substrate in the sulfamate electrolyte, in $3.5 \% \mathrm{NaCl}$. In that research, pure $\mathrm{Ni}$ and Co coatings and alloys with Co contents of 20, 50, 70 and $80 \%$ were studied. In both cases, $\mathrm{Ni}-20 \% \mathrm{Co}$ had the best corrosion resistance.

\section{Experimental}

All samples of substrate were cut in rectangular shapes with the dimensions of $8 \times 12 \mathrm{~cm}$ and $5 \times 2 \mathrm{~cm}$ from a mild steel plate with composition according to DIN EN 10025 and a thickness of $1 \mathrm{~mm}$, which was used as a cathode. A rolled nickel plate with $4 \mathrm{~mm}$ thickness and a surface 1.5 times larger than the cathode was chosen as the anode. Coatings were applied to one side of each sample, and the other side was painted by epoxy resin. Before electroplating all samples were labelled and polished using 100, 220, 500, 800 and 1000 grit emery papers, respectively. After degreasing and washing with distilled water, they were soaked in $10 \mathrm{wt} \%$ chloric acid for $30 \mathrm{~s}$, and finally, they were washed with distilled water and were dried with hot air. Then, their weights were recorded before entering into the electroplating bath.
Electrodeposition was carried out in a glass cubic cell with a volume of six litres by using a DC power supply with $4 \mathrm{~A}$ and $30 \mathrm{~V}$ output, and an air vacuum pump was used for agitation. The anode and the cathode were kept stationary and parallel to each other using a fixture. In the whole electroplating process, $\mathrm{NaOH}$ was added to the solution to keep the $\mathrm{pH}$ fixed at $2 \cdot 8$.

The alloy coating composition was determined by atomic adsorption spectroscopy (AAS). The solvent used for this purpose was $90 \mathrm{HNO}_{3} / 10 \mathrm{HCl}$. The thickness of coatings in this study was considered as 8 microns and the electroplating time was adjusted according to this thickness. Three different baths were used in order to achieve the desired alloy compositions according to table 1 .

The surface of coatings was studied by Nikon optical microscopy, model Eclipse E200, and scanning electron microscopy (SEM). To study the corrosion behaviour of coatings, three types of test, including atmospheric (Persian Gulf atmosphere) and accelerated (salt spray and electrochemical) tests were employed.

\section{Results and discussion}

It is seen from figure 1 that in solution 3 , as the overvoltage increases (up to $-1.25 \mathrm{~V}$ versus SCE), the amount of more noble metal (nickel) also increases. However, after that, the amount of less noble metal (cobalt) in the coating increases. This means that, in high-current densities (and, consequently, in high negative potentials), the electrodeposition shows anomalous behaviour while solution 2 does not have this behaviour.

\subsection{Corrosion results}

Kish Island, located in Persian Gulf, has a warm and wet climate most of the time. During the atmospheric tests, the island experienced various weather conditions. Persian Gulf has a marine climate, so chloride ion exists in its atmosphere as a corrosive ion. Besides that, some other pollutants like $\mathrm{SO}_{2}$ exist in this atmosphere. There is also a gas refinery in the west side of the island so its pollutants could be transferred to the island by wind. Another polluting agent is the electric power plant just one kilometre away from the atmospheric corrosion site. During the tests, the average relative humidity and temperature were found to be $66 \%$ and $29^{\circ} \mathrm{C}$, respectively, which shows critical corrosion conditions.

Table 1. Bath compositions used for electrodeposition.

\begin{tabular}{lccc}
\hline & $\begin{array}{c}\mathrm{NiSO}_{4} \cdot 6 \mathrm{H}_{2} \mathrm{O} \\
(\mathrm{M})\end{array}$ & $\begin{array}{c}\mathrm{CoSO}_{4} \cdot 7 \mathrm{H}_{2} \mathrm{O} \\
(\mathrm{M})\end{array}$ & $\begin{array}{c}\mathrm{H}_{3} \mathrm{BO}_{3} \\
(\mathrm{M})\end{array}$ \\
\hline Solution 1 & $0 \cdot 2$ & - & $0 \cdot 4$ \\
Solution 2 & $0 \cdot 2$ & $0 \cdot 001$ & $0 \cdot 4$ \\
Solution 3 & $0 \cdot 2$ & $0 \cdot 005$ & $0 \cdot 4$ \\
\hline
\end{tabular}




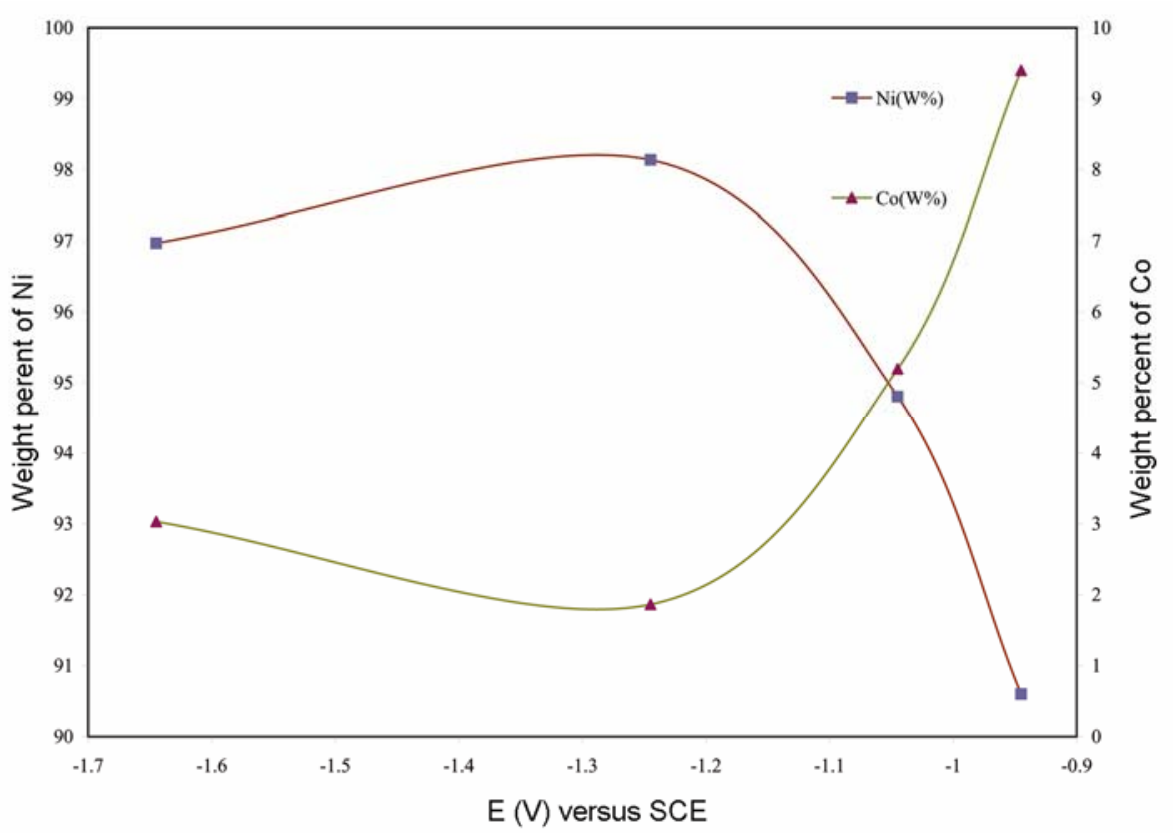

Figure 1. Composition of Ni-Co alloy deposits vs potential in solution 3 at $25{ }^{\circ} \mathrm{C}$ and $\mathrm{pH}=2 \cdot 8$.

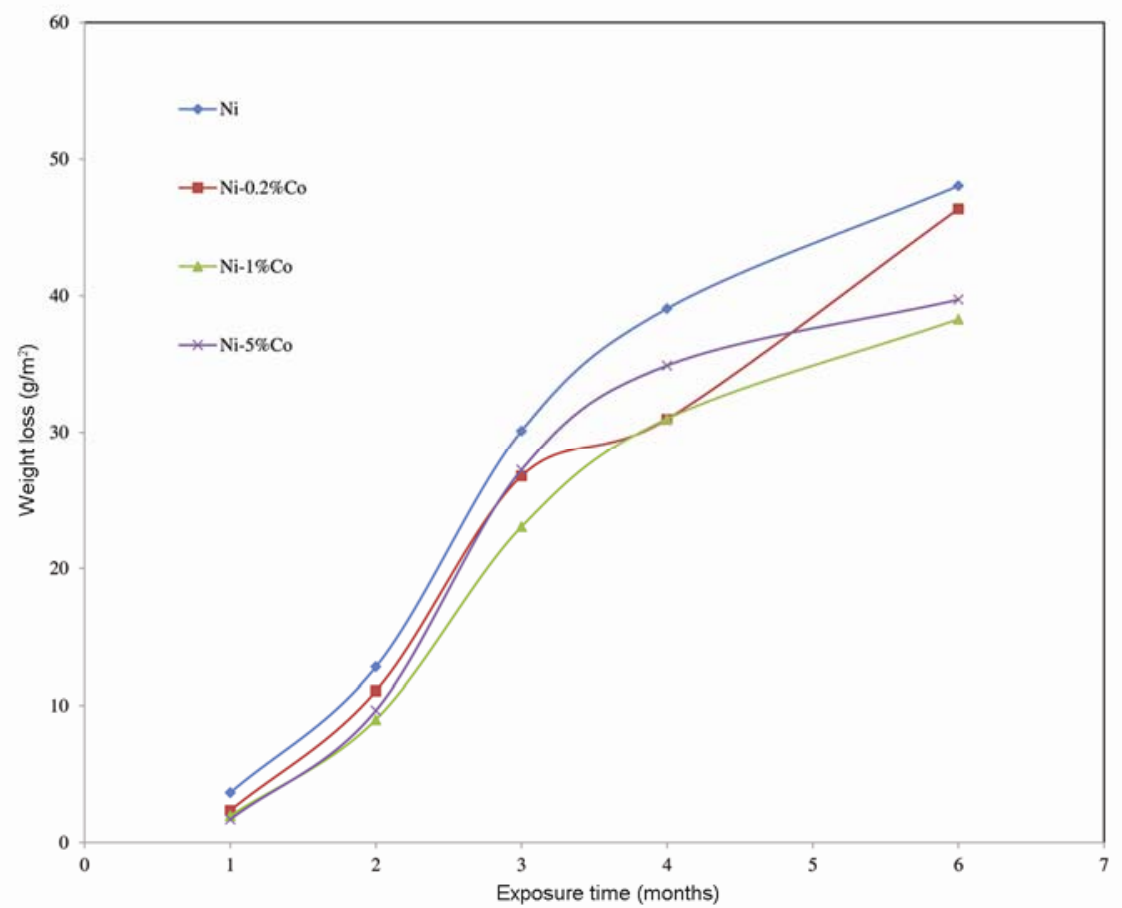

Figure 2. Weight loss curves of Ni-Co alloy coatings vs exposure time obtained from atmospheric test.

It is seen from figures 2 and 3 and table 2 that the existence of just $0.2 \%$ of Co can increase the corrosion resistance of the alloy. However, with an increase in the Co content to one percent, the best corrosion resistance was observed. On the contrary, pure nickel had the least corrosion resistance. Finally, in coatings with five-percent $\mathrm{Co}$, corrosion resistance decreased again.
The slope of curves in figure 2 is relatively sharp until third month, but its sharpness decreases in the fourth month due to the formation of oxide layer on the surface. These oxides are usually $\mathrm{NiO}$ and $\mathrm{Ni}(\mathrm{OH})_{2}$. These passive films can inhibit further corrosion or at least can reduce it. In the salt spray test (figure 3), the initial corrosion rate is high. Afterwards, a reduction in corrosion rate 
Table 2. Corrosion results of atmospheric and salt spray tests.

\begin{tabular}{llcccc}
\hline & Coating & $\mathrm{Ni}$ & $\mathrm{Ni}-0.2 \% \mathrm{Co}$ & $\mathrm{Ni}-1 \% \mathrm{Co}$ & $\mathrm{Ni}-5 \% \mathrm{Co}$ \\
\hline Average weight & Atmosphere* & $26 \cdot 72(0.41)$ & $23.49(0.35)$ & $20 \cdot 65(0 \cdot 30)$ & $22.63(0.33)$ \\
Change $\mathrm{g} / \mathrm{m}^{2}$ (mpy) & Salt spray** & $3.90(1 \cdot 2)$ & $3.7(1.07)$ & $3.16(0.92)$ & $3.5(1.04)$ \\
\hline
\end{tabular}

*The presented values of weight change and corrosion rate here are, in fact, the average of these values after 1, 2, 3, 4 and 6 months.

**The presented values of weight change and corrosion rate here are, in fact, the average of these values after 12, $24,48,72,120,168,216$ and $264 \mathrm{~h}$ in salt spray test.

Table 3. Electrochemical data of coatings in $3.5 \% \mathrm{NaCl}$ on steel substrate at $25{ }^{\circ} \mathrm{C}$.

\begin{tabular}{lccccc}
\hline Coating & $E_{\text {corr }}(\mathrm{mV})$ & $i_{\text {corr }}\left(\mathrm{A} / \mathrm{cm}^{2}\right)$ & $\beta_{\text {ox }}(\mathrm{mV} / \mathrm{dec})$ & $\beta_{\text {red }}(\mathrm{mV} / \mathrm{dec})$ & CPR $(\mathrm{mpy})$ \\
\hline $\mathrm{Ni}$ & -302 & $1 \cdot 27 \mathrm{E}-05$ & 58 & 146 & $5 \cdot 40$ \\
$\mathrm{Ni}-0.2 \% \mathrm{Co}$ & -212 & $1 \cdot 20 \mathrm{E}-05$ & $98 \cdot 6$ & 141 & $5 \cdot 10$ \\
$\mathrm{Ni}-1 \% \mathrm{Co}$ & -197 & $8 \cdot 82 \mathrm{E}-06$ & $98 \cdot 6$ & 128 & 3.75 \\
$\mathrm{Ni}-5 \% \mathrm{Co}$ & -227 & $1 \cdot 59 \mathrm{E}-05$ & 52 & 118 & $6 \cdot 77$ \\
\hline
\end{tabular}

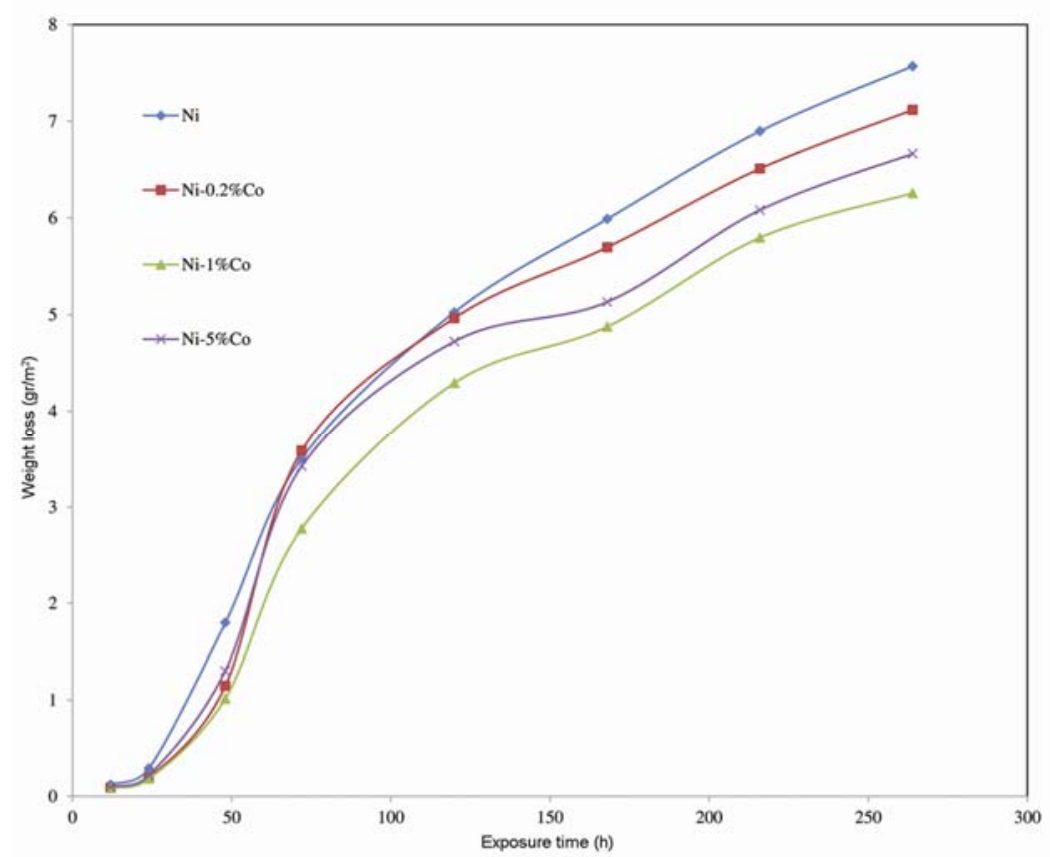

Figure 3. Weight loss curves of Ni-Co alloy coatings vs exposure time obtained from salt spray test.

is observed, which is due to the oxide or hydroxide passive layer formed on the surface. After that, due to the invasion of corrosive species such as chloride ion and wetness, the protective layer becomes unstable and, consequently, the corrosion rate increases again. Figure 4 and table 3 show the polarization curves and electrochemical data of the coatings. It is again seen that $\mathrm{Ni}-1 \% \mathrm{Co}$ alloy coating has the least corrosion rate $(3.75 \mathrm{mpy})$ and it is placed in the most positive potential range and these both mean that this coating has the best corrosion resistance.

During 20 days' exposure to the atmosphere, some fine red spots (about 7 spots per $96 \mathrm{~cm}^{2}$ ) appeared on the surface of samples. The size of these points and their number increased gradually with time $\left(45\right.$ spots per $96 \mathrm{~cm}^{2}$ after six months). A major corrosion did not appear after one month, but it increased after six months and the colour of some spots changed to gray. In the salt spray chamber, red spots were observed after $12 \mathrm{~h}$. Blistering started after $100 \mathrm{~h}$. Spot colours became gray at the end of the test $(264 \mathrm{~h})$, and this means that the coating has been removed completely at that point.

\subsection{Surface morphology and corrosion products}

Figure 5 shows the surface morphology of $\mathrm{Ni}-1 \% \mathrm{Co}$ provided by SEM. For simplicity, the images of corrosion products and EDX data of $\mathrm{Ni}-1 \%$ Co (the best corrosion 


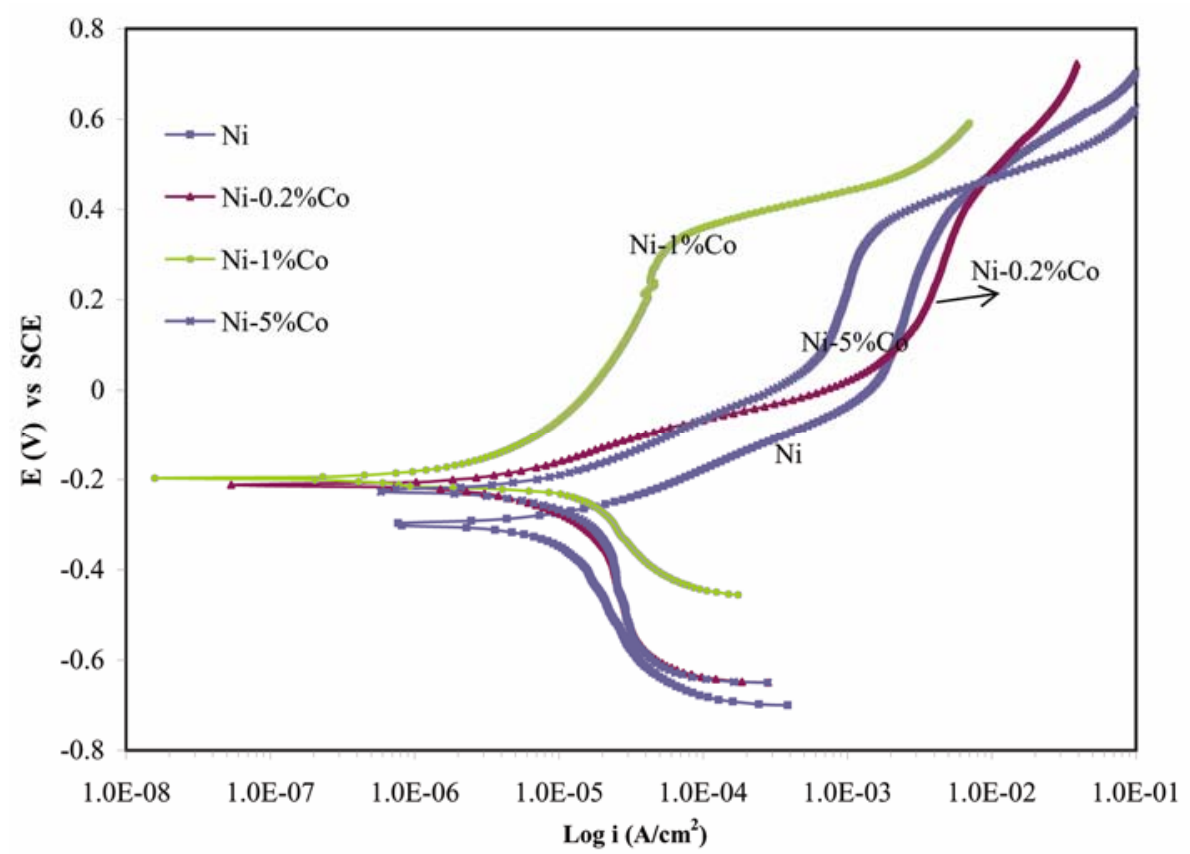

Figure 4. Polarization curves of Ni-Co alloy coatings deposited on steel substrate in $3.5 \% \mathrm{NaCl}$ at $25{ }^{\circ} \mathrm{C}$.

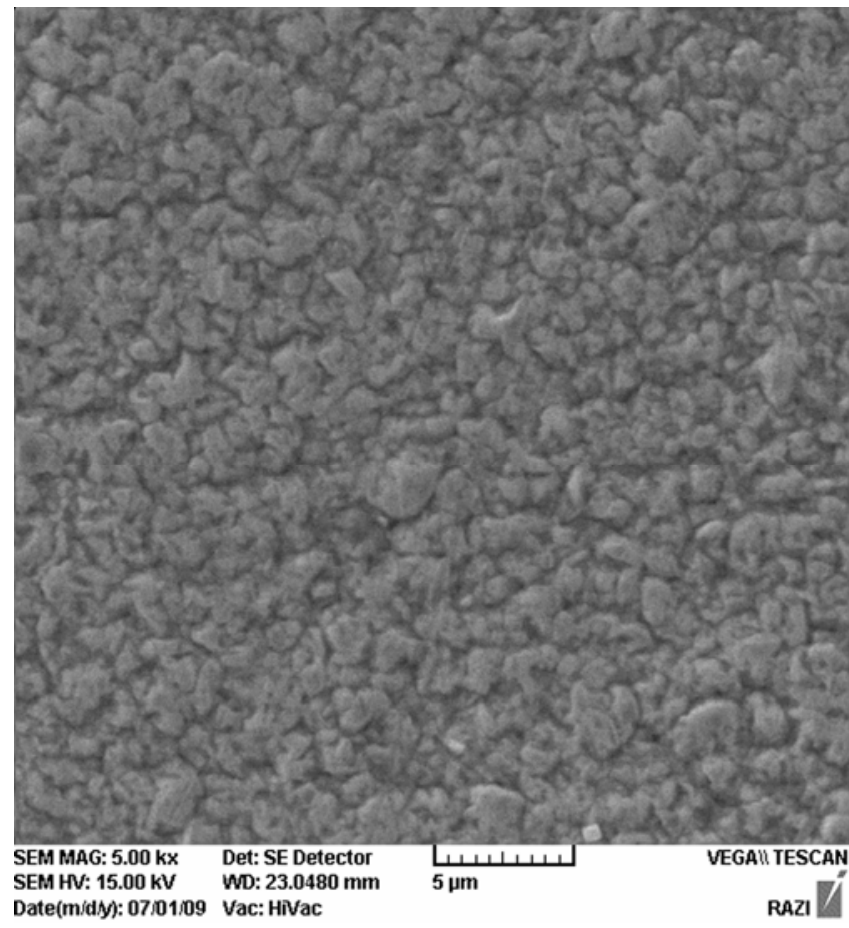

Figure 5. Surface morphology of $\mathrm{Ni}-1 \% \mathrm{Co}$ coating at $25^{\circ} \mathrm{C}$ and $\mathrm{pH}=2 \cdot 8, i=2 \mathrm{~A} / \mathrm{cm}^{2}$.

resistant), after one and six months, are compared. The images of corrosion products after one and six months, provided by optical microscopy, are shown in figures 6 and 7. After one month's exposure to Kish island atmosphere, a uniform corrosion was observed. But, after six

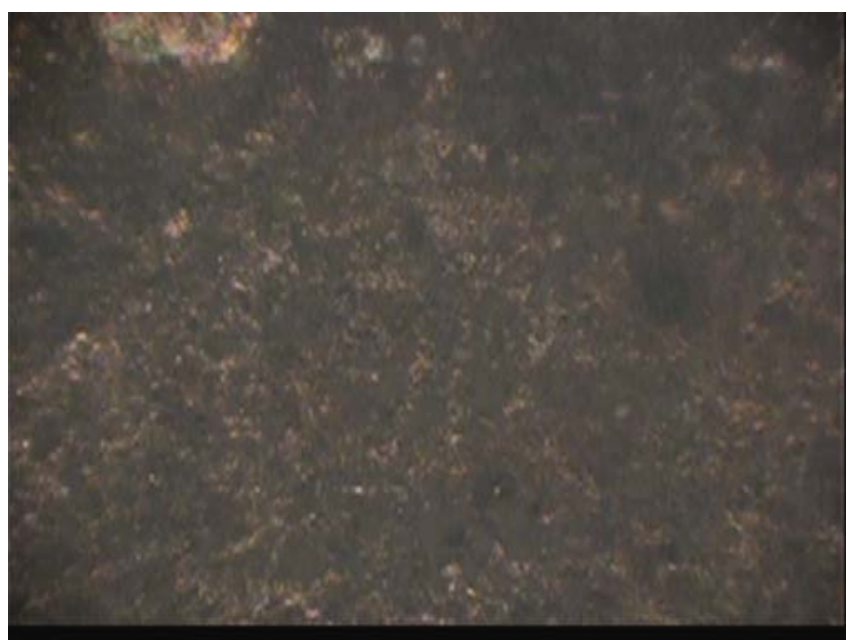

Figure 6. Surface image of $\mathrm{Ni}-1 \% \mathrm{Co}$ coating (provided by optical microscope at a magnification of $100 \times$ ) after one month's exposure to atmosphere.

months, a significant corrosion attack happened. Corrosion products have different colours such as green and brown, especially after six months. Most of the nickel components are green (oxide, hydroxide, carbonate, sulphate). So to distinguish what exactly the green areas are, more examinations are needed. The brown colour probably appeared as a result of substrate corrosion after six months.

SEM images of corrosion products of the same sample, after one and six months, are shown in figures 8 and 9. It is seen that the corrosion attack begins with cracks on the 
surface (shown by arrows in the pictures) and, then, it continues. After 6 months, the penetration of corrosion attack is remarkable.

EDX data of corrosion products of the mentioned sample are shown in figure 10. Some unexpected elements, like sulphur or silicon, for example, have probably come from suspending dust in the air and been transferred by wind on the coupons' surface. The presence of oxygen, sulphur and chlorine can lead us to have chlorides, sulphides and

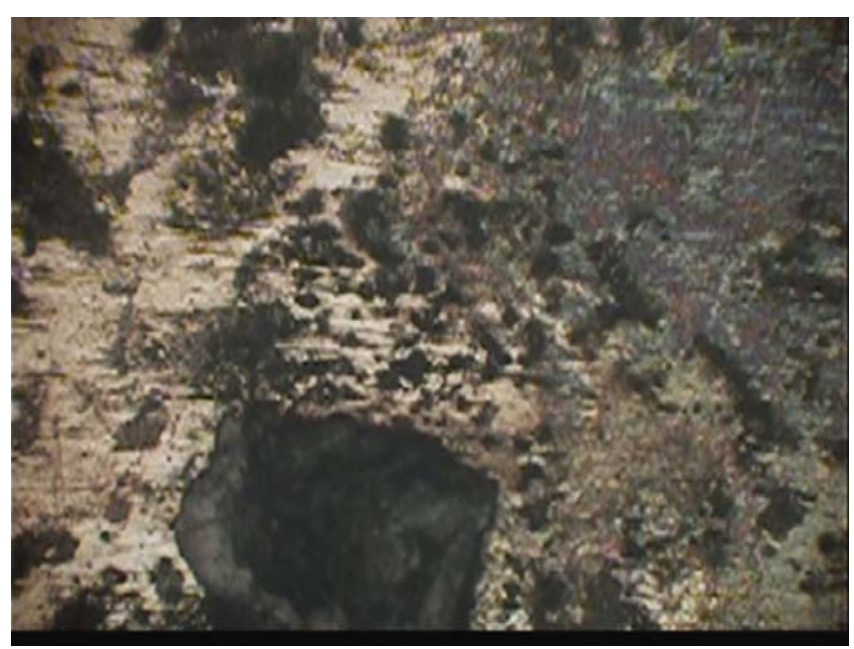

Figure 7. Surface image of $\mathrm{Ni}-1 \% \mathrm{Co}$ coating (provided by optical microscope at a magnification of $100 \times$ ) after six months' exposure to atmosphere.

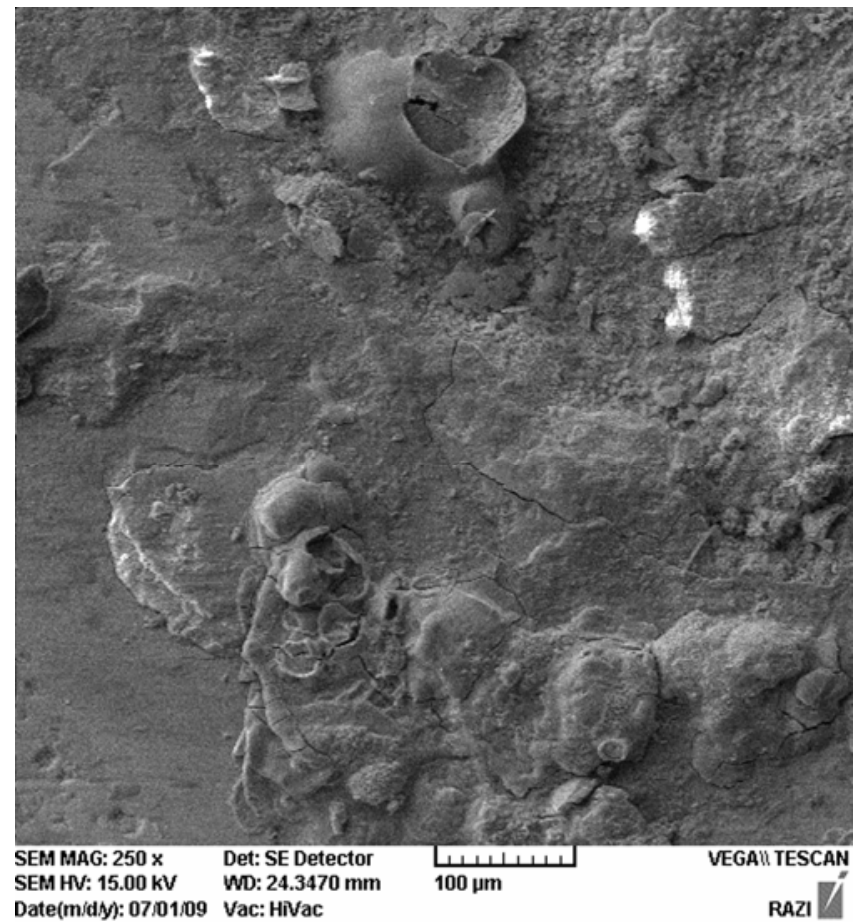

Figure 8. SEM image of surface of $\mathrm{Ni}-1 \% \mathrm{Co}$ coating after one months' exposure to the atmosphere. oxides in the corrosion products. Molecular oxygen has rapid physical adsorption and good ability to accept electrons. Therefore, after gaining the metallic coating electrons, chemisorptions of atomic oxygen to form an oxide or hydroxide monolayer happen and nickel ions transfer to the environment. Further electrons pass through this layer and second, third or more layers may form. As long as these layers are less porous and more stable, a better corrosion protection is achieved. Chlorine and sulphur ions can form $\mathrm{HCl}$ or $\mathrm{H}_{2} \mathrm{SO}_{4}$ and accelerate corrosion. Water in the form of dew or in bulk (like rain) acts as electrolyte. This provides a passage for the flow of current and any surface imperfections or grain boundaries play the role of anode and cathode.

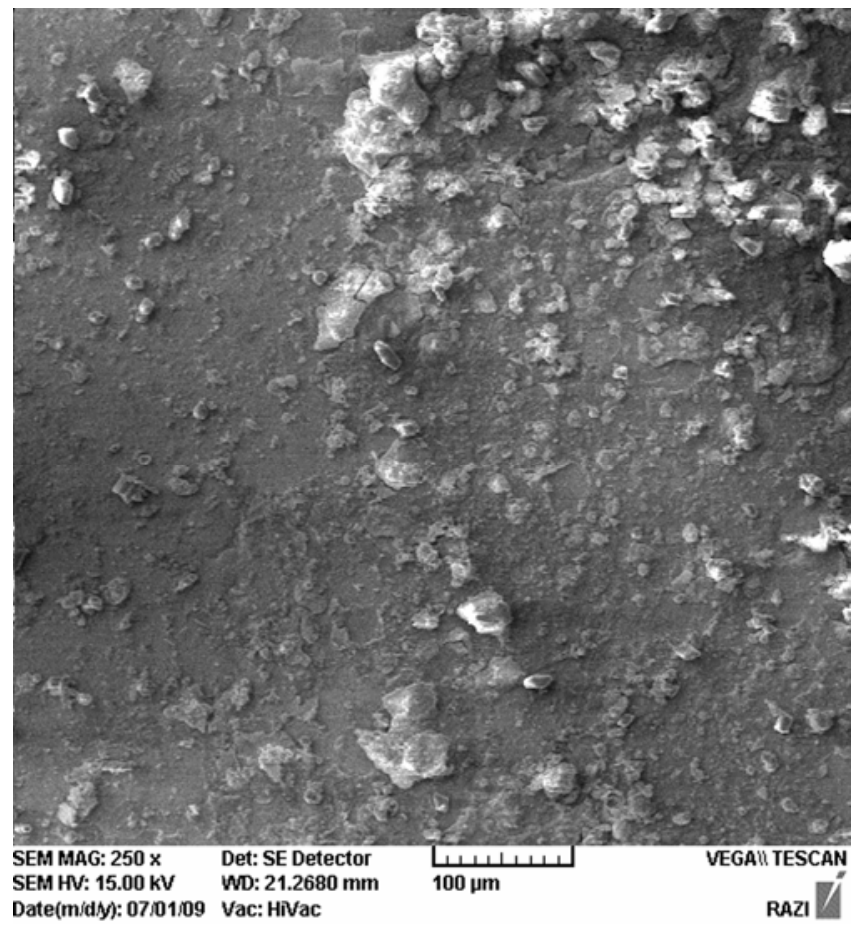

Figure 9. SEM image of surface of $\mathrm{Ni}-1 \% \mathrm{Co}$ coating after six months exposure to the atmosphere.

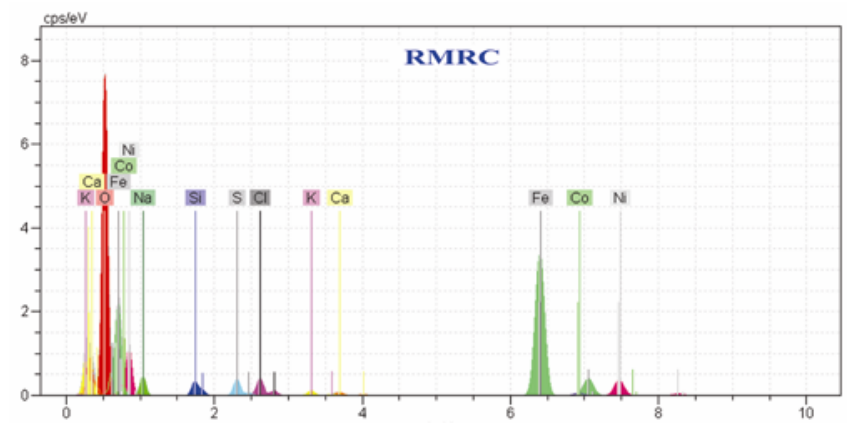

Figure 10. EDX spectrum of corrosion products on $\mathrm{Ni}-1 \% \mathrm{Co}$ coating surface after six months' exposure to atmosphere. 


\section{Conclusions}

This study proved that the solution with low cobalt content (sulphate solution contains $0.001 \mathrm{~mol} / \mathrm{lit} \mathrm{CoSO}_{4}$ ) does not show anomalous behaviour. But, as the cobalt content $\left(0 \cdot 005 \mathrm{~mol} / \mathrm{lit} \mathrm{CoSO}_{4}\right)$ and electroplating voltage increase, it shows anomalous behaviour. All three corrosion tests consist of atmospheric (Kish island atmosphere), salt spray and polarization (in $\mathrm{NaCl} 3.5 \%$ ) tests. These show that $\mathrm{Ni}-1 \% \mathrm{Co}$ alloy coating with corrosion rate of $0.30,0.92$ and $3.75 \mathrm{mpy}$, respectively, has the best corrosion resistance. Corrosion products analyzed by EDX demonstrate the existence of sulphur, chlorides and oxides that probably were brought on the coating's surface by dust and wind and are able to accelerate the corrosion rate. It is shown that in both atmospheric and salt spray tests, the slope of the corrosion rate-time curve is initially high, and then it decreases. This can be the result of a passive layer film such as $\mathrm{NiO}$ or $\mathrm{Ni}(\mathrm{OH})_{2}$ formed on the coupon's surface.

\section{References}

Ahmad Zaki 2006 Principles of corrosion engineering and corrosion control (Elsevier Science and Technology Books) pp 414, 415, 536, 550

ASM Handbook 1992 Corrosion, 9th edn, USA, Vol. 13, pp 80, 641

ASM Handbook 1993 Properties and selection: nonferrous alloys and special-purpose materials 10th edn, USA, Vol. 2, pp 428, 446

ASM Handbook 1994 Surface engineering 10 edn, USA, Vol. 5 , pp 201

Chi Bo, Li Jianbao, Yang Xiaozhan, Gong Yanli and Wang Ning 2005 Inter. J. Hydrogen Energy 3029

Cisse Mbouille, Abouchane Mohamed, Anik Tayeb, Himm Karima, Belakhmima Allah Rida, Touhami Mohamed Ebn, Touir Rachid and Amiar Abderrahmane 2010 Int. J. Corros. p 9
Correia A N and Machado S A S 2000 Electrochem. Acta 45 1733

Dolati A, Sababi M, Nouri E and Ghorbani M 2007 Mater. Chem. Phys. 102118

Ebadi Mehdi, Basirun W J and Alias Yatimah 2010 J. Chem. Sci. 122279

Eliaz N, Venkatakrishna K and Chitharanjan Hegde A 2010 Surf. Coat. Technol. 2051969

Golodnitsky D, Yu Rosenberg and Ulus A 2002 Electrochem. Acta 472707

Lupi C and Pilone D 2001 Miner. Eng. 141403

Meenu Srivastava, Ezhil Selvi V, William Grips V K and Rajam K S 2006 Surf. Coat. Technol. 2013051

Orinakova Renata, Orinak Andrej, Vering Guido, Talian Ivan, Smith Roger M and Heinrich F Arlinghaus 2008 Thin Solid Films 5

Qiao Guiying, Jing Tianfu, Wang Nan, Gao Yuwei, Zhao Xin, Zhou Jifeng and Wang Wei 2005 Electrochem. Acta 5185

San Nalan Oya and Nazir Hasan 2010 Commun. Fac. Sci. Univ. Ank. Series B 561

Schweitzer Philip A 2004 Encyclopedia of corrosion technology (New York: Marcel Dekker INC), 2nd edn, pp 44, 51, 147, 407

Schweitzer Philip A 2006 Corrosion control through organic coatings pp 149

Schweitzer Philip A 2007 Corrosion engineering handbook, fundamentals of metallic corrosion, atmospheric and media corrosion of metals (USA: CRC Press) 2nd edn, pp 39, 42, $49,52,54$

Shreir L L, Jarman R A and Burstein G T 2000 Corrosion, metal/environment reaction (England: ButterworthHeinemann) 3rd edn, Vol. 1, Ch. 2, pp 31, 35, Ch. 4, p 121

Tury B, Lakatos-Varsanyi M and Roy S 2006 Surf. Coat. Technol. 2006713

Tury B, Lakatos-Varsanyi M and Roy S 2007 Appl. Surf. Sci. 2533103

Tury B, Radnoezi G Z, Radnoezi G and Varsanyi M L 2007 Surf. Coat. Technol. 202331

Wang G F, Chan K C and Zhang K F 2006 Scr. Mater. 54765

Wang Liping, Gao Yan, Xue Qunji, Liu Huiwen and Xu Tao 2005 Appl. Surf. Sci. 242326

Wolfgang E G Hansal, Barbara Tury, Martina Halmdienst, Magda Lakatos Varsanyi and Wolfgong Kautek 2006 Electrochem. Acta $\mathbf{5 2} 1145$ 